\title{
USE OF SHERPA FOR THE PREVENTION OF HUMAN ERRORS AMONG AGRICULTURAL MACHINERY USERS
}

\author{
MASSIMO GUARASCIO ${ }^{1}$, MARIO FARGNOLI $^{1}$, MARA LOMBARDI $^{1}$, \\ DANIELE PURI ${ }^{2} \&$ FABIO GARZIA $^{1}$ \\ ${ }^{1}$ Faculty of Civil and Industrial Engineering of Sapienza University of Rome, Italy \\ ${ }^{2}$ Department of Technological Innovations and Safety of Plants, Products and Anthropic Settlements, \\ National Institute for Insurance against Accidents at Work, Italy
}

\begin{abstract}
Despite the ever stricter safety regulations and standards, the number of accidents in the agricultural sector is still relevant. The reports on occupational accidents in this sector highlight that most serious and fatal accidents are related to both the use of machinery that are not in conformity with safety protection requisites, and their misuse. The present study aims to investigate the latter aspect, focusing on the analysis of human error by means of the Systematic Human Error Reduction and Prediction Approach (SHERPA) method. In particular, we analyse the operators' behaviour and risk perception while performing agricultural activities with pedestrian controlled self-propelled machines. Results achieved show the lack of safety awareness, especially among self-employed and part-time agricultural workers, fostering the need for a more consistent effort to improve information and communication on safety issues among farmers.
\end{abstract}

Keywords: occupational safety, machinery safety, human error, SHERPA, human safety, agriculture.

\section{INTRODUCTION}

Safety in the agriculture sector still represent a relevant problem at a global level [1]-[3]. In fact, despite the great effort made in recent years by lawmakers in issuing stricter regulations concerning both occupational and machinery safety, the number of accidents and victims has not significantly decreased [4], [5]. The main factors causing this situation are related to the peculiar characteristics of the agricultural works, which can be summarized in the following main aspects: the frequent employees' turnover, the seasonal works' deadlines, the outdoor works in all weather conditions, the lack of highly trained workers, the use of obsolete working equipment, the frequent change of work sites, etc. [6], [7].

In particular, the reports on occupational accidents in this sector highlight that the majority of serious and fatal accidents are related to the use of machinery that are not in conformity with safety protection requisites, as well as to their misuse [8], [9]. In this study, we focused on the latter aspect, since the human behaviour plays a key role on the accident causality [10]. In fact, the identification and analysis of the hazardous events that might occur during working activities considering the human behaviour perspective can augment the quality of risk assessment activities, providing more effective results for risk reduction and prevention measures [11]-[13].

In literature, numerous studies addressing this goal can be found, mainly concerning the analysis of safety critical industries, as for example: nuclear plants, marine systems, railway and aviation industry, chemical plants, etc. [14], [15]. Conversely, in the agricultural sector, few studies have addressed these issues, mainly focusing on the ergonomics' aspects of human behaviour [16], [17]. Moreover, most studies addressing safety issues while using agricultural machinery concerned the use of four-wheel (or continuous track) tractors, while other working equipment, such as two-wheel tractors (2WTs), motor hoes or rotary tillers are still scarcely considered [18], [19]. 
The reasons of such a situation are due to the fact that compared with the four-wheel tractors, the accidents occurred while using the latter usually have a minor severity and caused less fatalities according to official statistics. However, their great diffusion also among non-professional users [20], as well as the fact that they do not need to be officially registered since they are not considered vehicles by the current legislation make it difficult to estimate the incidence of accidents and their effects properly. On these considerations, the purpose of the present study consists in investigating the human errors related to the use of two-wheel tractors by means of the Systematic Human Error Reduction and Prediction Approach (SHERPA) method [21]. Accordingly, in collaboration with authorities for occupational health and safety, farmers were interviewed in order to depict the context and define both the critical tasks and the related hazardous situations. Then, human errors were identified and assessed using SHERPA. The study brought to light the underestimation of potential risks by the operators, providing useful information for the implementation of safe solutions from both the management, and the engineering point of view.

\section{BACKGROUND ANALYSIS}

\subsection{Context definition}

In rural areas, agricultural pedestrian controlled self-propelled machines are highly diffused due to their multipurpose applications. In fact, starting from a common base consisting of an engine, a frame containing the gear and the power transmission, and a handle-bars command system, they can be used for driving, pulling or being equipped with different working tools depending on the different uses [19], [22]. More in detail, following the criteria provided by the EN 709:1997 standard [23], this type of equipment can be classified into the following categories. 2WTs are single-axle tractors (also called "walking tractors") characterized by a power take-off aimed at driving and/or pulling working tools (Fig. 1).

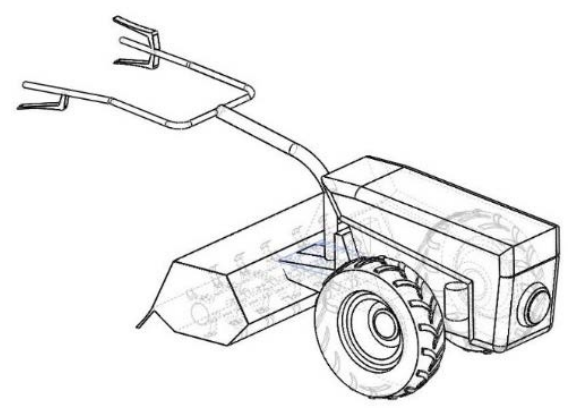

Figure 1: Scheme of a two-wheel tractor (2WT).

Instead, in motor hoes (with or without supporting wheels) the propulsion is guaranteed by the working elements directly actuated by the engine. The latter type of machinery can be also equipped with drive wheels directly actuated by the engine.

Studies concerning safety issues while using this type of machinery are not numerous and mostly addressed the problems related to vibrations. In particular, Tewari and Dewangan [24] studied the vibrations transmitted by $2 \mathrm{WTs}$, proposing rubber isolators for engine mountings and handles to reduce their effects on the operators. Similarly, Chaturvedi et al. [25] reported a field analysis of vibration reduction using polyurethane and rubber isolators, as well as their 
combination during the different use phases of 2WTs. Guo et al. [26] analysed the handle vibrations in comparison with those at the engine cover in a motor motor-hoe. Sam and Kathirvel [27] focused their attention on hand vibrations, pointing out that also the correct use of the equipment (e.g. holding handles without straining arms, avoiding a tight grip of handles, etc.) has a significant impact on the transmission of vibrations. Accordingly, Heidary et al. [28] investigated the discomfort caused by vibrations, which may cause to operators Comfort limit and some symptoms like headache, influence on speech and lump in the throat. Besides, the comfort of operators was studied also by workloads Tiwari and Gite [29], who considered different types of discomfort while operating a $2 \mathrm{WT}$ leading physiological and postural.

Other studies on this type of equipment focused on their use as a transportation means especially in rural areas of developing countries, where the main concerns are related to road safety [18], [30], [31]. It has to be noted that in other countries, although is still diffused, this use of the equipment is not always allowed by safety and road traffic regulations. As for example, in Italy 2 WTs and motor hoes need to undergo a specific approval in order to be considered as road mobile machinery. Otherwise, they cannot be considered as "vehicles".

\subsection{Accident statistics}

Although this type of equipment is usually associated to a large number of accidents among those occurred when dealing with agricultural machinery, it is very difficult to estimate their real impact on accident statistics. As a matter of fact, official statistics consider them into the category of "accidents with agricultural machinery", without specifying the type of machine/equipment involved. Besides, we also have to take into account the fact that most of the users of this type of equipment are not professional users. Moreover, we also have to consider that in most countries (e.g. in the European Union) official statistics do not include the accidents occurred to self-employed workers. Hence, it is difficult to find detailed information on this phenomenon at an official level.

Conversely, if we consider data concerning the accidents registered taking into account reports of both police departments and inspectors of the national health service, numbers are indeed larger. In Table 1 this type of data collected by the Observatory on accidents in agriculture of INAIL [32] related to the period 2013-2017 are shown.

Table 1: Accident related to the use of agricultural pedestrian controlled self-propelled machines [32].

\begin{tabular}{|c|c|c|}
\hline Years & Serious injuries & Fatalities \\
\hline 2013 & 50 & 14 \\
\hline 2014 & 34 & 10 \\
\hline 2015 & 31 & 20 \\
\hline 2016 & 28 & 11 \\
\hline 2017 & 28 & 12 \\
\hline Total & 171 & 67 \\
\hline
\end{tabular}

Hence, on the one hand, this remarkable difference in numbers between data registered for regular employees and observatory data shows that this phenomenon and its impact on farmers is underestimated.

On the other hand, despite data provided by the observatory cannot be considered significant from the statistical point of view [32], they can provide qualitative information 
that can be useful to understand the characteristics of the phenomenon. More in detail, qualitative information on the number of the registered accidents classified based on the age of victims is shown in Fig. 2, while the type of accidents, i.e. the circumstances or mode in which the accident occurred in the period 2013-2017 is reported in Table 2 [32].

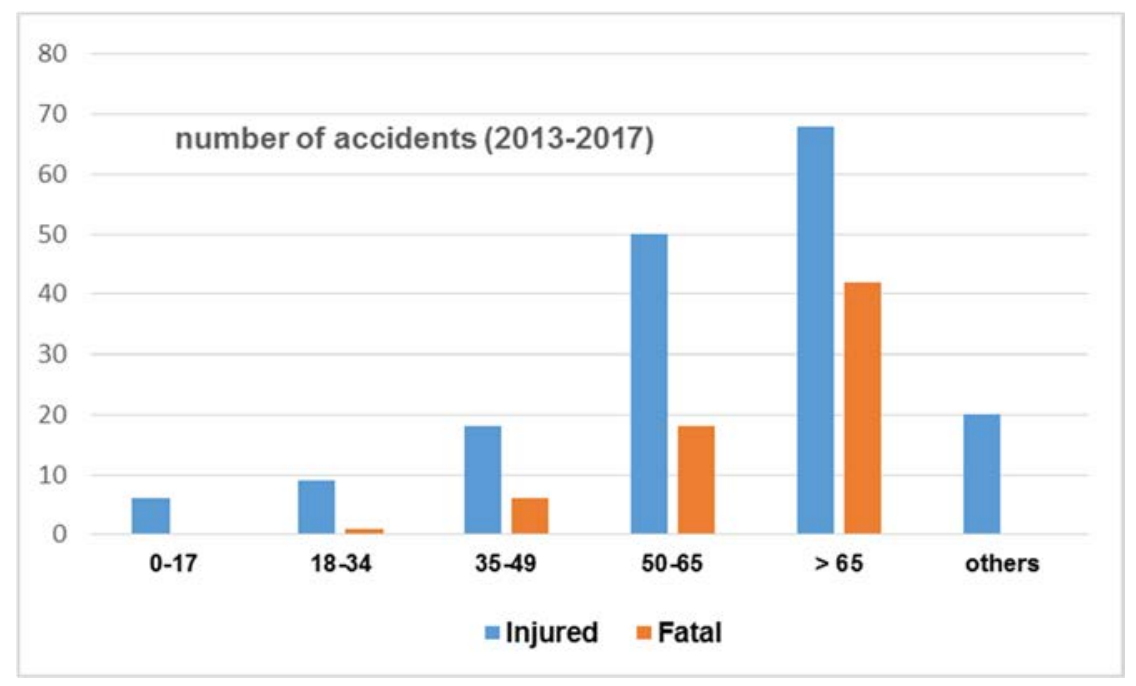

Figure 2: Number of accidents registered by the observatory of INAIL divided according to the age of victims. (Source: Adapted from [32].)

Table 2: Circumstances or mode of the accident in the period 2013-2017. (Source: Adapted from [32].)

\begin{tabular}{|l|c|c|}
\hline Circumstances & Injuries & Fatal accidents \\
\hline Contact/entanglement with moving parts & 146 & 46 \\
\hline Crashing & 8 & 10 \\
\hline Roll over & 12 & 9 \\
\hline Impact with objects & 1 & 1 \\
\hline Others & 4 & 1 \\
\hline Total & 171 & 67 \\
\hline
\end{tabular}

\subsection{Research issues}

In such a context, despite the large number of accidents occurring to farmers needing safety and reliability analyses of human functions are needed to allow an improvement of performances and well-being [34]. most studies concerned the use of traditional tractors (i.e. four-wheel tractors), and the misperception of their safe conditions by users [35]-[39]. Other studies remarkably focused on the proper comprehension of pictograms [40] and safety signs [41] on agricultural machinery.

Instead, the analysis of the operators' behaviour and risk perception while performing agricultural activities with pedestrian controlled self-propelled machines has been scarcely investigated in literature. To reduce this gap, in this study the Systematic Human Error 
Reduction and Prediction Approach (SHERPA) method [21] was used with the goal of identifying human error types and predicting their occurrence with reference to the use of pedestrian controlled self-propelled machinery.

\section{RESEARCH APPROACH}

\subsection{The SHERPA method}

More in detail, following the SHERPA method a distinction of the possible human failures can be made into the following categories [21]:

1. Action errors (A), when the human action changes the status of the system.

2. Checking errors (C), when the operator fails to verify, check the status of the system.

3. Retrieval errors $(\mathrm{R})$, if the operator fails to retrieve information, e.g. from a working procedure.

4. Communication errors $(\mathrm{C})$, when the operator fails to transfer information to other personnel.

5. Selection errors $(\mathrm{S})$, when the operator makes the wrong choice among different alternatives.

Each one of the above categories is characterized by different error modes, as shown in Table 3.

Table 3: SHERPA error modes. (Source: Adapted from [42].)

\begin{tabular}{|l|ll|}
\hline Error category & Error mode \\
\hline A. Action errors & A1 & Operation too long/short \\
& A2 & Operation mistimed \\
& A3 & Operation in wrong direction \\
& A4 & Operation too little/much \\
& A5 & Misalign \\
& A6 & Right operation on wrong object \\
& A7 & Wrong operation on right object \\
& A8 & Operation omitted \\
& A9 & Operation incomplete \\
& A10 & Wrong operation on wrong object \\
\hline C. Checking errors & C1 & Check omitted \\
& C2 & Check incomplete \\
& C3 & Right check on wrong object \\
& C4 & Wrong check on right object \\
& C5 & Check mistimed \\
& C6 & Wrong check on wrong object \\
\hline R. Retrieval errors & R1 & Information not obtained \\
& R2 & Wrong information obtained \\
& R3 & Information retrieval incomplete \\
\hline I. Communication errors & I1 & Information not communicated \\
& I2 & Wrong information communicated \\
& I3 & Information communication incomplete \\
\hline S. Selection errors & S1 & Selection omitted \\
& S2 & Wrong selection made \\
\hline
\end{tabular}


In order to apply the method, an analysis of the working tasks performed is needed. As suggested by Ghasemi et al. [43], this activity is focused on bringing to light the individual's perception of task to reach goals in accordance with the working procedures and/or the instructions received. In order to perform this activity, the Hierarchical Task Analysis (HTA) method [44] was used. The output of the method consists in filling the SHERPA tables, where to each task type error modes are associated and evaluated considering the recovery possibility, the consequences, the probability of occurrence and criticality of the error (e.g. by means of a qualitative ranking such as: low, medium or high), as well as the remedial measures [21].

\subsection{The case study}

The case study was carried out through a series of interviews with 19 users of pedestrian controlled self-propelled machinery. More in detail, seven users of motor-hoes; three users of motor-hoes with drive wheels; and nine users of 2WTs were interviewed separately. Most of them are self-employed farmers, who uses this equipment to operate in fields where fourwheel tractors cannot be used due to space limits (e.g. in vineyards or vegetable gardens). Others are part-time agricultural workers or hobbyists. More in detail, the interviews were structured as follows:

- Definition of the main activities the task "use of the equipment" can be split in by means of a bottom up approach: i.e. the task is divided in sub-tasks; each sub-task is divided in elementary activities.

- Analysis of each activity with reference to the error classification provided in Table 3.

- Definition of error modes.

The results of the questionnaires were analysed by a group of experts in order to define the consequences of each error and the recovery opportunities of potential identified errors. Based on this an assessment of the risk level associated to each potential error was carried out using a qualitative scale ( $\mathrm{L}=$ low; $\mathrm{M}=$ medium; $\mathrm{H}=$ high) for estimating both the probability of occurrence and the criticality of the potential errors [21].

\section{RESULTS}

In Fig. 3 the results of the task analysis are shown. It has to be noted that since the interviewed operators were not using exactly the same equipment, we only selected the activities that are in common among all of them, while additional operations (e.g. plowing) that can be carried out only by means of $2 \mathrm{WTs}$ were not taken into account. As far as the transit is concerned, the use of additional wheels was considered when the equipment is used on the road. Moreover, from the interviews it emerged that towing an agricultural trailer is quite common since $79 \%$ of interviewed operators use the equipment equipped with a trailer for reaching working areas as well as for carrying goods (e.g. wood, fruit, etc.).

For each of the above elementary activity, the error modes were identified, and the SHERPA tables were implemented accordingly: in Table 4 an excerpt of the SHERPA table concerning the use of a trailer is shown.

In total, 42 human errors were identified: 19 Action errors; six Control errors; nine Retrieval errors; two Communication errors; and six Selection errors. In Fig. 4 the status of the identified errors is shown, where the most significant ones concern the failure in completing an operation correctly. 


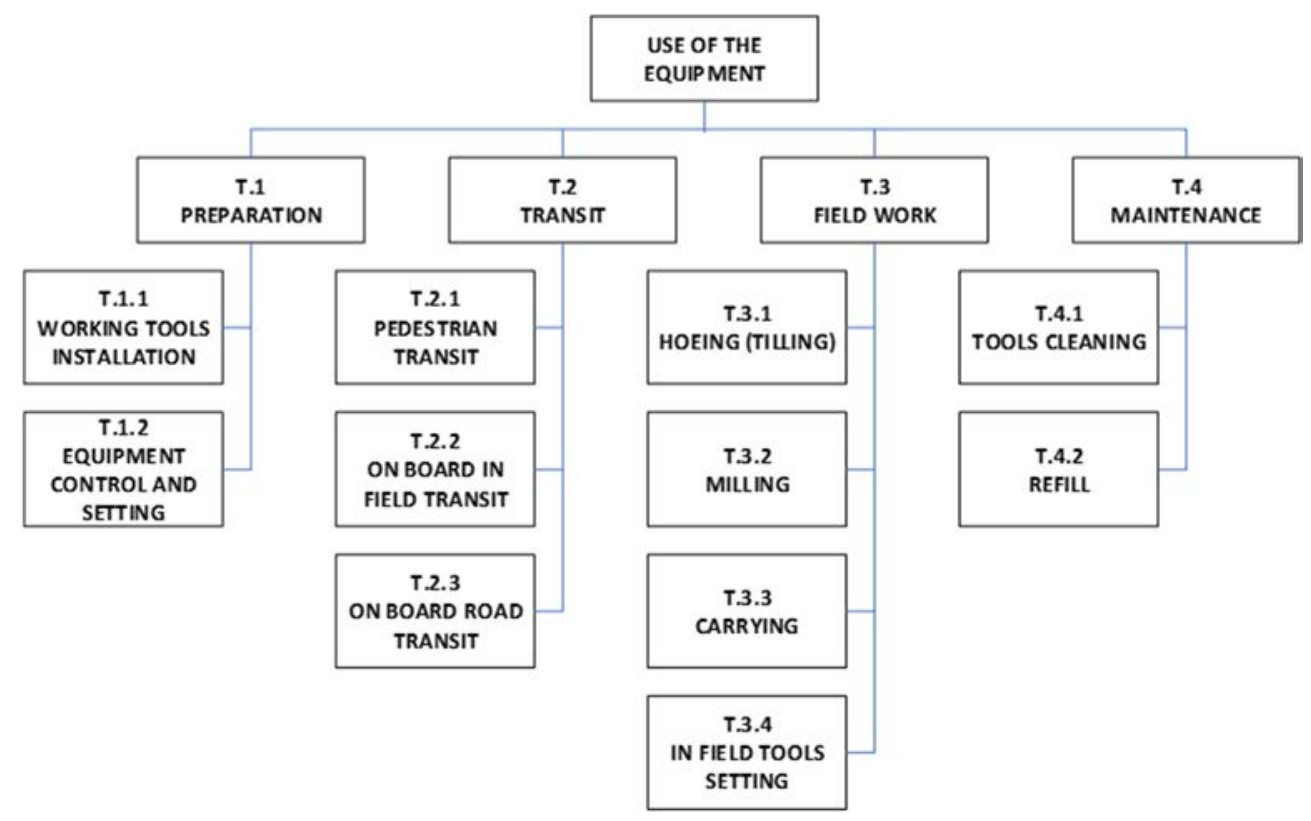

Figure 3: Hierarchical task analysis of the working activities.

Table 4: Excerpt of the SHERPA method application.

\begin{tabular}{|c|c|c|c|c|c|c|}
\hline Activity & $\begin{array}{l}\text { Error } \\
\text { mode }\end{array}$ & Description & Consequence & Recovery & Probability & Criticality \\
\hline \multirow{5}{*}{ T.1.1 } & A2 & $\begin{array}{l}\text { The operator installs } \\
\text { the transit wheels } \\
\text { without checking if } \\
\text { the equipment is } \\
\text { braked }\end{array}$ & $\begin{array}{l}\text { Crushing, } \\
\text { entanglement }\end{array}$ & T.2.1 & L & $\mathrm{M}$ \\
\hline & $\mathrm{C} 1$ & $\begin{array}{l}\text { The operator installs } \\
\text { the transit wheels } \\
\text { without checking if } \\
\text { the equipment is } \\
\text { cooled down }\end{array}$ & $\begin{array}{l}\text { Contact with } \\
\text { high } \\
\text { temperature } \\
\text { parts }\end{array}$ & T.2.1 & M & $\mathrm{L}$ \\
\hline & A6 & $\begin{array}{l}\text { The operator does } \\
\text { not use the proper } \\
\text { personal protective } \\
\text { equipment (e.g. } \\
\text { gloves, overalls) }\end{array}$ & $\begin{array}{l}\text { Contact with } \\
\text { cutting parts } \\
\text { Entanglement }\end{array}$ & & $\mathrm{H}$ & $\mathrm{L}$ \\
\hline & A9 & $\begin{array}{l}\text { The operator has not } \\
\text { fixed the wheels } \\
\text { properly }\end{array}$ & $\begin{array}{l}\text { Loss of stability } \\
\text { Crushing } \\
\text { Exposure to } \\
\text { vibrations }\end{array}$ & Т.2.1 & $\mathrm{L}$ & $\mathrm{H}$ \\
\hline & S2 & $\begin{array}{l}\text { The operator uses } \\
\text { wrong transport } \\
\text { wheels }\end{array}$ & $\begin{array}{l}\text { Loss of stability } \\
\text { Crushing } \\
\text { Exposure to } \\
\text { vibrations }\end{array}$ & T.2.1 & $\mathrm{L}$ & $\mathrm{H}$ \\
\hline
\end{tabular}




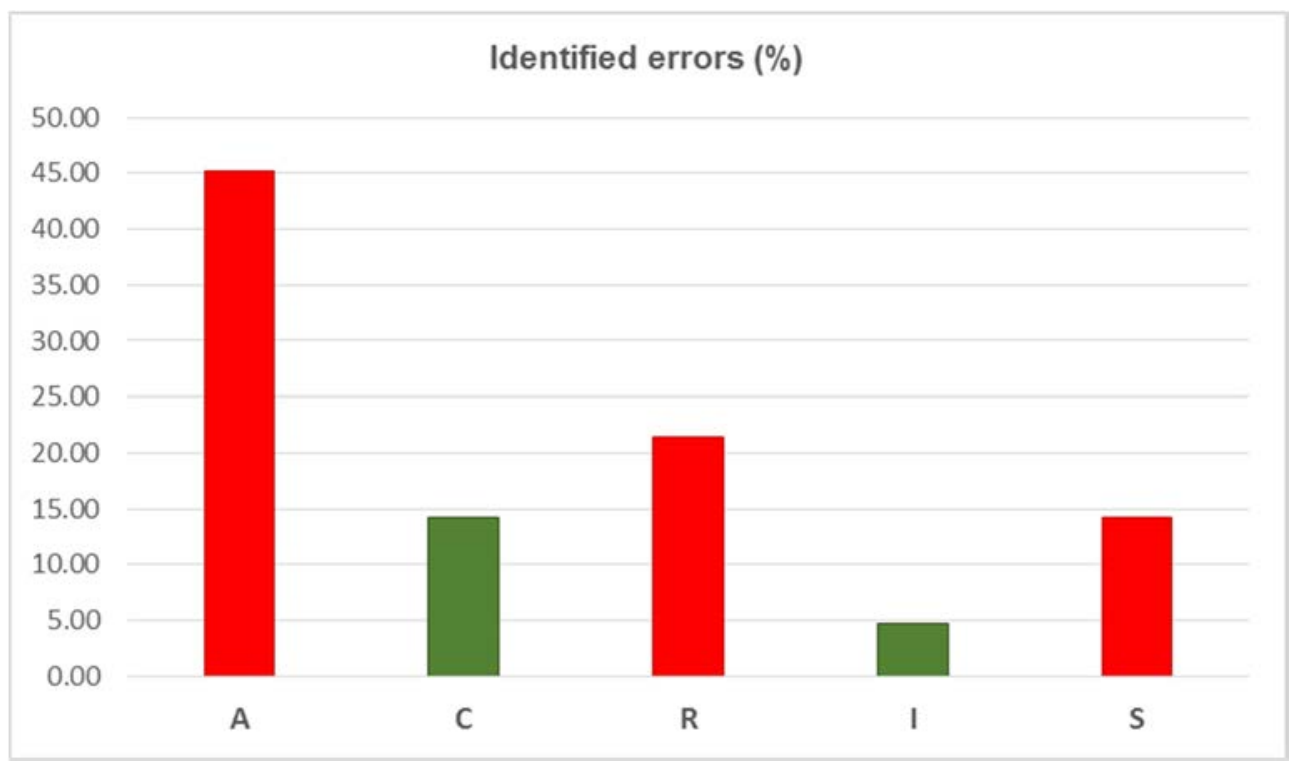

Figure 4: Percentage of the identified errors. $\mathrm{A}=$ Action errors; $\mathrm{C}=$ Checking errors; $\mathrm{R}=$ Retrieval errors; $\mathrm{I}=$ Communication errors; $\mathrm{S}=$ Selection errors.

\section{DISCUSSION OF RESULTS}

The results obtained show that most of errors are action type: in particular, A2 (operation mistimed) and A7 (wrong operation on right object) are the most common in accordance with the responses of the operators. Besides, retrieval errors were also considered frequent, especially during the transportation and transit operations.

On the one hand, such an output reflects the type of operators interviewed: in fact, since they are not company employees, they do not have to follow strict working procedures. This can lead them to omit or underestimate safety issues, making it difficult to choose the right action after an error in order to bring the system to a safe condition. On the other hand, the results are in line with data provided with the INAIL's observatory [32], where most of serious/fatal accidents are related to wrong operations. This accomplishes the research clues by Cividino et al. [36], who pointed out the low perception and awareness of safety issue by the workers in the agricultural sector. Accordingly, as demonstrated also in other fields [45], [46], safety perception and climate in small working contexts need to be augmented, in order to reduce the number of accidents.

At a more general level, these results bring to light the need to improve safety information and training among farmers, considering the large number of self-employed operators and small sized companies. This is in line with the observations provided by Cavallo et al. [47], who stressed on the little attention paid to the condition of the working equipment.

Thus, the use of the SHERPA method resulted in being effective in pinpointing the safety perception and awareness of workers, bringing to light error types that can be hardly identified following a top-down analysis [48], [49]. Furthermore, such an approach can support engineers in better analysing the interactions among operators, technical systems, working environment, showing improvement options both from the technical and managerial point of view [43], [50]. 
Beside these positive aspects, we have to underline that the present study also presents some limitations mainly due to both the small number of interviewed operators and to the difficulties that non-expert analysts can find in applying the SHERPA method [51]. Hence, although the use of a single case-study as a research tool for exploratory investigation and to generate new understandings is recognized [52], the generalization of the research findings needs to be supported by the application of the proposed approach to further and larger analysis.

\section{CONCLUDING REMARKS}

Given the large number of accidents among workers in the agricultural sector especially when using working equipment, the analysis of safety perception and awareness of operators has become relevant. In such a context, the use of tools for the identification of human errors certainly represents a viable approach to augment knowledge in this research field.

This study contributes to the current research literature by proposing the application of the SHERPA method for the analysis of human errors in agricultural activities. Results achieved showed the low safety perception of self-employed and part-time workers when dealing with pedestrian controlled self-propelled machines. Such a finding can be considered exploratory and used to define new research questions and promote further and more detailed analysis.

\section{REFERENCES}

[1] Jadhav, R., Achutan, C., Haynatzki, G., Rajaram, S. \& Rautiainen, R., Risk factors for agricultural injury: A systematic review and meta-analysis. Journal of Agromedicine, 20(4), pp. 434-449, 2015.

[2] Zheng, L. et al., Nonfatal work-related injuries among agricultural machinery operators in northern China: A cross-sectional study. Injury, 45(3), pp. 599-604, 2014.

[3] Houshyar, E. \& Houshyar, M., Tractor safety and related injuries in Iranian farms. Safety Science, 103, pp. 88-93, 2018.

[4] Cecchini, M. et al., Survey on the status of enforcement of European directives on health and safety at work in some Italian farms. Journal of Food, Agriculture and Environment, 11(3-4), pp. 595-600, 2013.

[5] Lombardi, M. \& Fargnoli, M., Prioritization of hazards by means of a QFD-based procedure. International Journal of Safety and Security Engineering, 8(2), pp. 342353, 2018.

[6] Moradhaseli, S., Farhadian, H., Abbasi, E. \& Ghofranipour, F., Factors affecting the incidence of occupational accidents among farmers. Health Education and Health Promotion, 5(1), pp. 39-56, 2017.

[7] Fargnoli, M., Vita, L., Gattamelata, D., Laurendi, V. \& Tronci, M., A reverse engineering approach to enhance machinery design for safety. Proceedings of DESIGN 2012, Dubrovnik, Croatia, pp. 627-636, 2012.

[8] Mishra, D. \& Satapathy, S., A framework designed for macro-ergonomical analysis of Indian farmers: assessment and analysis of occupational injuries of agricultural farmers of South Odisha in India. Advanced Macroergonomics and Sociotechnical Approaches for Optimal Organizational Performance, IGI Global, pp. 162-183, 2019.

[9] Robert, K., Elisabeth, Q. \& Josef, B., Analysis of occupational accidents with agricultural machinery in the period 2008-2010 in Austria. Safety Science, 72, pp. 319-328, 2015.

[10] Irwin, A. \& Poots, J., The human factor in agriculture: An interview study to identify farmers' non-technical skills. Safety Science, 74, pp. 114-121, 2015. 
[11] Schwab, C.V., Mosher, G.A. \& Ryan, S.J., Agricultural worker injury comparative risk assessment methodology: Assessing corn and biofuel switchgrass production systems. Journal of Agricultural Safety and Health, 23(3), pp. 219-235, 2017.

[12] Narasimhan, G., Crowe, T.G., Peng, Y., Hagel, L., Dosman, J. \& Pickett, W., A taskbased analysis of machinery entanglement injuries among Western Canadian farmers. Journal of Agromedicine, 16(4), pp. 261-270, 2011.

[13] Llory, M., Human-and work-centred safety: Keys to a new conception of management. Ergonomics, 40, pp. 1148-1158, 1997.

[14] Alvarenga, M.A.B., Melo, P.F. \& Fonseca, R.A., A critical review of methods and models for evaluating organizational factors in human reliability analysis. Progress in Nuclear Energy, 75, pp. 25-41, 2014.

[15] Borghini, F., Garzia, F., Lombardi, M., Mete, M., Perruzza, R. \& Tartaglia, R., Human factor analysis inside a peculiar job environment at the Gran Sasso mountain underground laboratory of Italian National Institute for Nuclear Physics. International Journal of Safety and Security Engineering, 8(3), pp. 390-405, 2018.

[16] Tiecheng, Z., The study on the ergonomics of hand tractor based on digital human model. Proceedings of the Sixth International Conference on Measuring Technology and Mechatronics Automation, IEEE, pp. 778-781, 2014.

[17] Patel, T., Sanjog, J. \& Karmakar, S., Ergonomics perspective in agricultural research: A user-centred approach using CAD and digital human modeling (DHM) technologies. Journal of The Institution of Engineers (India): Series A, 97(3), pp. 333-342, 2016.

[18] Ericson, M., Two-wheel tractors: Road safety issues in Laos and Cambodia. Safety Science, 48(5), pp. 537-543, 2010.

[19] Tiwari, P.S. \& Gite, L.P., Physiological responses during operation of a rotary power tiller. Biosystems Engineering, 82(2), pp. 161-168, 2002.

[20] Rathnayaka, N., Amadoru, I., Gunathilaka, H. \& Chamara, A., Performance evaluation of a two wheel tractor (Sonik mini cultivator). Proceedings of 17th Agricultural Research Symposium, pp. 163-167, 2018.

[21] Harris, D., Stanton, N.A., Marshall, A., Young, M.S., Demagalski, J. \& Salmon, P., Using SHERPA to predict design-induced error on the flight deck. Aerospace Science and Technology, 9(6), pp. 525-532, 2005.

[22] Rasool, S. \& Raheman, H., Improving the tractive performance of walking tractors using rubber tracks. Biosystems Engineering, 167, pp. 51-62, 2018.

[23] EN 709:1997+A4:2009, Agricultural and forestry machinery. Pedestrian controlled tractors with mounted rotary cultivators, motor hoes, motor hoes with drive wheel(s). Safety. European Committee for Standardization: Geneva, 2009.

[24] Tewari, V.K. \& Dewangan, K.N., Effect of vibration isolators in reduction of work stress during field operation of hand tractor. Biosystems Engineering, 103(2), pp. 146$158,2009$.

[25] Chaturvedi, V., Kumar, A. \& Singh, J.K., Power tiller: Vibration magnitudes and intervention development for vibration reduction. Applied Ergonomics, 43(5), pp. 891-901, 2016.

[26] Guo, L., Jian, C., Hangjia, X. \& Shimeng, W., Vibration test and analysis of minitiller. International Journal of Agricultural and Biological Engineering, 9(3), pp. 97103.

[27] Sam, B. \& Kathirvel, K., Vibration characteristics of walking and riding type power tillers. Biosystems Engineering, 95(4), pp. 517-528, 2006. 
[28] Heidary, B., Hassan-Beygi, S.R. \& Ghobadian, B., Ergonomic characteristics and operator body fatigue against two-wheel tractor vibration. International Journal of Agriculture and Crop Sciences, 5(4), pp. 370-376, 2013.

[29] Tiwari, P.S. \& Gite, L.P., Evaluation of work-rest schedules during operation of a rotary power tiller. International Journal of Industrial Ergonomics, 36(3), pp. 203210, 2006.

[30] Kumar, G.P. \& Dewangan, K.N., Agricultural accidents in north eastern region of India. Safety Science, 47(2), pp. 199-205, 2009.

[31] Kim, B., Yum, S., Kim, Y.Y., Yun, N., Shin, S.Y. \& You, S., An analysis of factors relating to agricultural machinery farm-work accidents using logistic regression. Journal of Biosystems Engineering, 39(3), pp. 151-157, 2014.

[32] National Institute for Insurance against Accidents at Work (INAIL), Osservatorio nazionale sugli incidenti in agricoltura (National observatory on occupational accidents in agriculture), 2018.

[33] Lombardi, M. \& Rossi, G., Cluster analysis of fatal accidents series in the Infor.mo database: Analysis, evidence and research perspectives. International Journal of Safety and Security Engineering, 3(4), pp. 317-331, 2013.

[34] Caffaro, F., Cremasco, M.M., Giustetto, A., Vigoroso, L., Paletto, G. \& Cavallo, E., Ergonomics in agriculture: critical postures, gestures, and perceived effort in handling foldable roll-over protective structures (ROPS) fitted on tractors. Proceedings of the Congress of the International Ergonomics Association. Springer: Cham, pp. 194-202, 2018.

[35] Houshyar, E. \& Houshyar, M., Tractor safety and related injuries in Iranian farms. Safety Science, 103, pp. 88-93, 2018.

[36] Cividino, S.R.S., Pergher, G., Zucchiatti, N. \& Gubiani, R., Agricultural health and safety survey in Friuli Venezia Giulia. Agriculture, 8(1), p. 9, 2018.

[37] Fargnoli, M., Lombardi, M., Haber, N. \& Puri, D., The impact of human error in the use of agricultural tractors: A case study research in vineyard cultivation in Italy. Agriculture, 8(6), p. 82, 2018.

[38] Hollnagel, E., Reliability analysis and operator modelling. Reliability Engineering and System Safety, 52(3), pp. 327-337, 1996.

[39] Irwin, A., Caruso, L. \& Tone, I., Thinking ahead of the tractor: Driver safety and situation awareness. Journal of Agromedicine, pp. 1-10, 2019.

[40] Caffaro, F., Schmidt, S., Murphy, D.J. \& Cavallo, E., Comprehension rates of safety pictorials affixed to agricultural machinery among Pennsylvania rural population. Safety Science, 103, pp. 162-171, 2018.

[41] Vigoroso, L., Caffaro, F. \& Cavallo, E., Warning against critical slopes in agriculture: comprehension of targeted safety signs in a group of machinery operators in Italy. International Journal of Environmental Research and Public Health, 16(4), p. 611, 2019.

[42] Stanton, N.A. \& Baber, C., Error by design: Methods for predicting device usability. Design Studies, 23(4), pp. 363-384, 2002.

[43] Ghasemi, M., Nasleseraji, J., Hoseinabadi, S. \& Zare, M., Application of SHERPA to identify and prevent human errors in control units of petrochemical industry. International Journal of Occupational Safety and Ergonomics, 19(2), pp. 203-209, 2013.

[44] Stanton, N.A., Hierarchical task analysis: Developments, applications, and extensions. Applied Ergonomics, 37, pp. 55-79, 2006. 
[45] Khosravi, Y., Asilian-Mahabadi, H., Hajizadeh, E., Hassanzadeh-Rangi, N., Bastani, H. \& Behzadan, A.H., Factors influencing unsafe behaviors and accidents on construction sites: A review. International Journal of Occupational Safety and Ergonomics, 20(1), pp. 111-125, 2014.

[46] Fargnoli, M. \& Lombardi, M., Preliminary Human Safety Assessment (PHSA) for the improvement of the behavioral aspects of safety climate in the construction industry. Buildings, 9(3), p. 69, 2019.

[47] Cavallo, E., Ferrari, E., Bollani, L. \& Coccia, M., Attitudes and behaviour of adopters of technological innovations in agricultural tractors: A case study in Italian agricultural system. Agricultural Systems, 130, pp. 44-54, 2014.

[48] Hughes, C.M., Baber, C., Bienkiewicz, M., Worthington, A., Hazell, A. \& Hermsdörfer, J., The application of SHERPA (Systematic Human Error Reduction and Prediction Approach) in the development of compensatory cognitive rehabilitation strategies for stroke patients with left and right brain damage. Ergonomics, 58(1), pp. 75-95, 2015.

[49] Fargnoli, M., Lombardi, M., Haber, N. \& Guadagno, F., Hazard function deployment: A QFD-based tool for the assessment of working tasks: A practical study in the construction industry. International Journal of Occupational Safety and Ergonomics, pp. 1-22, 2018.

[50] Di Pasquale, V., Miranda, S., Iannone, R. \& Riemma, S., A simulator for human error probability analysis (SHERPA). Reliability Engineering and System Safety, 139, pp. 17-32, 2015.

[51] Lane, R., Stanton, N.A. \& Harrison, D., Applying hierarchical task analysis to medication administration errors. Applied Ergonomics, 37(5), pp. 669-679, 2006.

[52] Yin, R.K., Case Study Research: Design and Methods, 4th ed., Sage: Thousand Oaks, CA, 2008. 